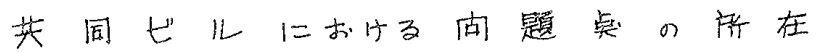

正会堅传藤則夫

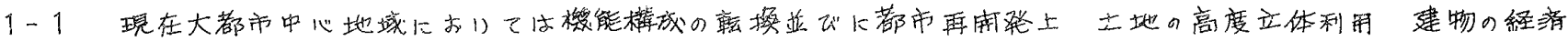

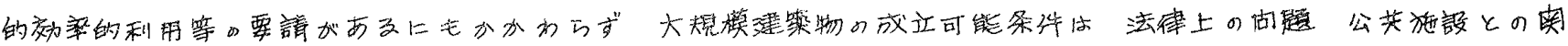

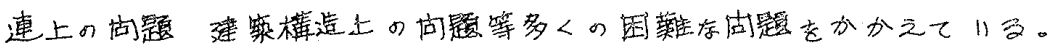

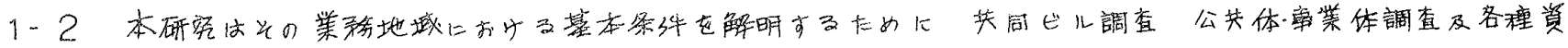

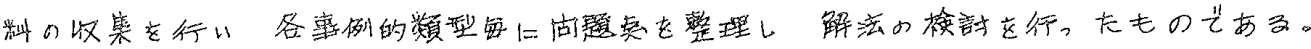

2- 1 问题点の整理

\begin{tabular}{|c|c|c|c|c|}
\hline \multicolumn{2}{|c|}{ 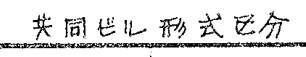 } & 整地区分 & 形態区分 & 南题 虔 \\
\hline \multirow{3}{*}{ 区分新有世代 } & 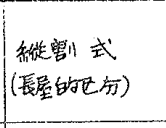 & 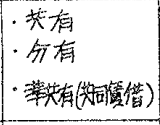 & 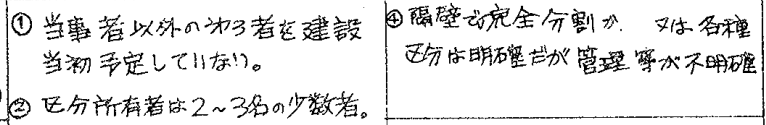 & 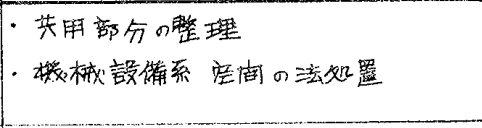 \\
\hline & 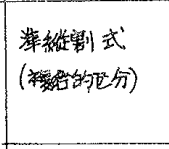 & 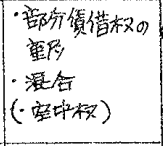 & \multirow{2}{*}{ 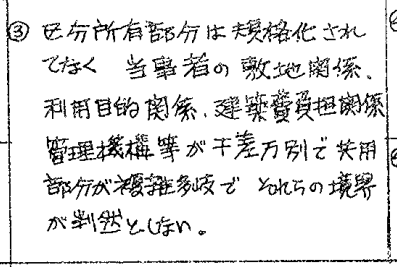 } & 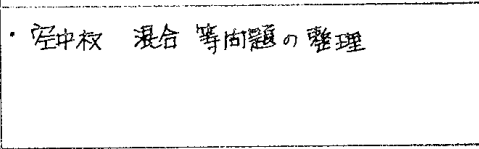 \\
\hline & 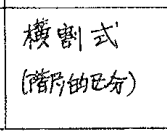 & 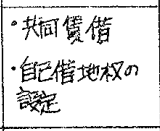 & & 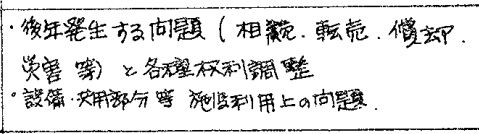 \\
\hline \multicolumn{2}{|c|}{ 芙有ビル } & 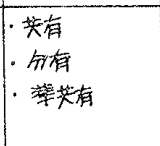 & 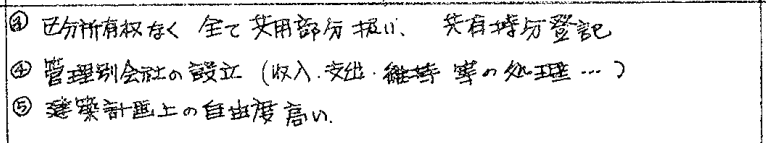 & - 共同管理借制の法的処琶 \\
\hline \multicolumn{2}{|c|}{ 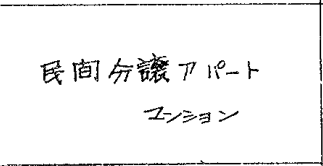 } & 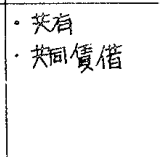 & 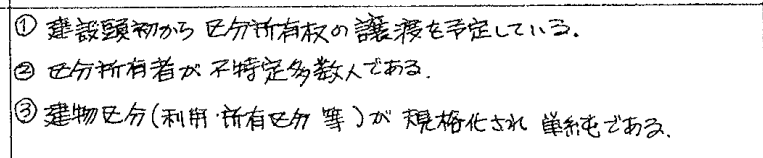 & 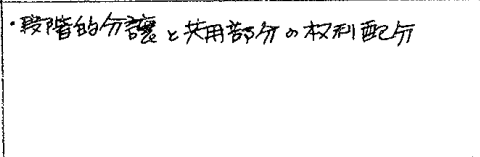 \\
\hline \multicolumn{2}{|c|}{$\begin{array}{r}\text { 市徍地施設付住宅 } \\
\text { (住定公国) }\end{array}$} & 䨳错 & 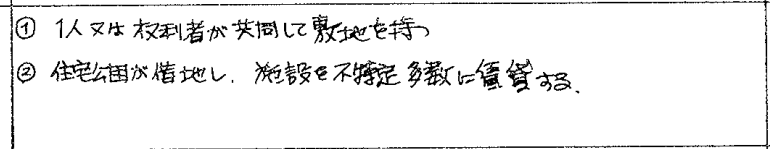 & 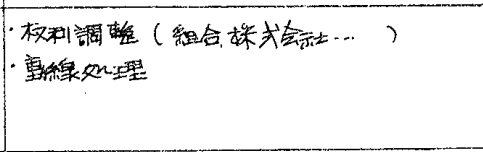 \\
\hline \multicolumn{2}{|c|}{ 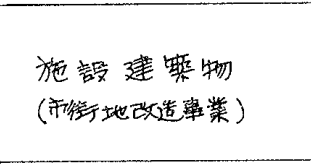 } & 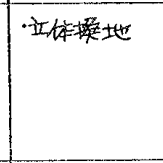 & 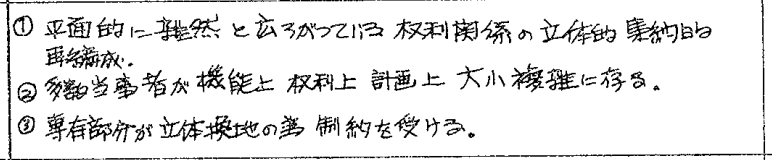 & 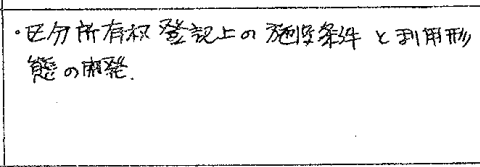 \\
\hline \multicolumn{2}{|c|}{ 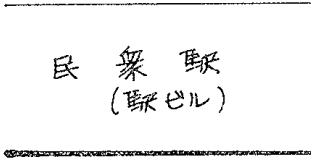 } & 便用䚺可 & 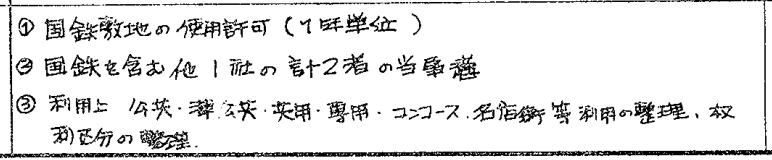 & 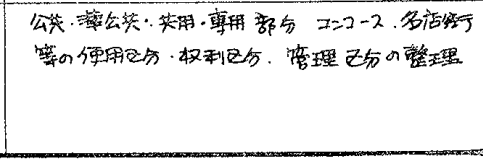 \\
\hline
\end{tabular}

\title{
$2-2$ 榙哭
}

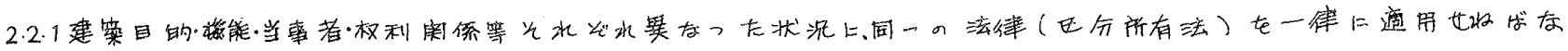

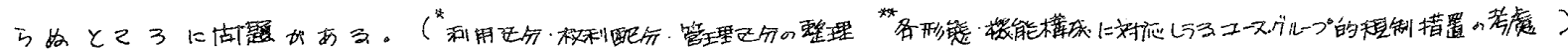

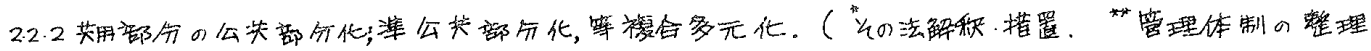

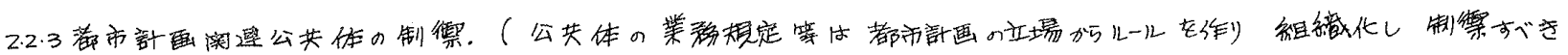
ものでஙる。)

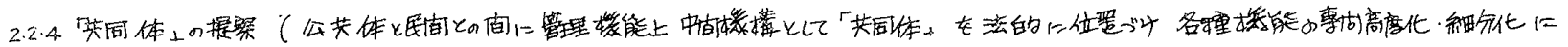
好尤子世及. )

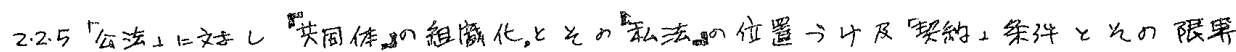

